\title{
Endothelial prostacyclin protects the kidney from ischemia-reperfusion injury
}

\author{
Yingxue Cao $^{1} \cdot$ Yi Guan $^{1} \cdot$ Yun-Yu Xu ${ }^{1} \cdot$ Chuan-Ming Hao ${ }^{1}$
}

Received: 12 June 2018 / Revised: 11 October 2018 / Accepted: 23 October 2018 / Published online: 9 November 2018

(C) The Author(s) 2018

\begin{abstract}
Prostacyclin, or $\mathrm{PGI}_{2}$, is a product of PGI synthase (PGIS), down-stream of cyclooxygenase pathway. $\mathrm{PGI}_{2}$ has been demonstrated to play an important role in maintaining renal blood flow. Non-steroidal anti-inflammatory drugs (NSAIDs) that inhibit cyclooxygenase are reported to increase the susceptibility of patients to acute kidney injury (AKI). This study explores the role of endothelium-derived prostacyclin in ischemia-reperfusion injury (I/RI). The renal PGIS expression and $\mathrm{PGI}_{2}$ production markedly increased following I/RI. Loss of one allele of PGIS gene or selective endothelial PGIS deletion (TEK-CRE PGIS ${ }^{\text {fl/fl }}$ mice) caused more severe renal damage following I/RI than control mice. Iloprost, a $\mathrm{PGI}_{2}$ analog, administered $30 \mathrm{~min}$ before the I/R surgery, markedly attenuated the renal damage in both control mice and TEK-CRE PGIS ${ }^{\mathrm{fl} / \mathrm{fl}}$ mice. Renal p-PKA expression significantly increased after I/RI in wild-type mice but not in the PGIS deletion mice, consistent with IP receptor mediating the protective effect. Further studies showed that PGIS deficiency was associated with reduced fluorescence microsphere accumulation in the kidney following I/R. Folic acid also induced marked kidney injury; however, endothelial PGIS deletion did not worsen kidney injury compared with wild-type mice. These studies indicate that PGIS-derived $\mathrm{PGI}_{2}$ can protect the kidney from acute injury caused by ischemia and reperfusion and $\mathrm{PGIS} / \mathrm{PGI}_{2}$ is a potential intervention target for AKI.
\end{abstract}

Keywords Prostacyclin $\cdot$ Ischemia-reperfusion injury $\cdot$ IP receptor $\cdot$ Renal blood flow

\section{Introduction}

Acute kidney injury (AKI) is a global public concern that is associated with high morbidity, mortality, and healthcare costs, and is increasingly prevalent in both developing and developed countries $[24,27,42]$. Ischemia-reperfusion injury (I/RI) is the most common cause of AKI [2, 43]. Although extensive studies have been performed over the past decades, the incidence of AKI remains high, and therapies are limited. Furthermore, renal I/RI is almost unavoidable in renal transplantation [25], which may contribute significantly to delayed graft function (DGF). Additionally, up to $30 \%$ of the patients receiving cardiac surgery may experience acute kidney injury [36]. Other than dialysis, no pharmacological treatments reliably improve survival, limit injury, or accelerate recovery [47].

Chuan-Ming Hao

chuanminghao@fudan.edu.cn

1 Division of Nephrology, Huashan Hospital, Fudan University, 12 Wulumuqi Road (middle), Shanghai 200040, China
Prostacyclin, or $\mathrm{PGI}_{2}$, is a member of the prostaglandin family. $\mathrm{PGI}_{2}$ is one of the end metabolites of arachidonic acid that is produced via cyclooxygenase (COX) and PGI synthase (PGIS) $[5,32,37] . \mathrm{PGI}_{2}$ has a half-life of $30 \mathrm{~s}$ and is metabolically degraded to 6-Keto $\mathrm{PGF}_{1 \alpha}$. The short half-life limits its effect to the site of synthesis $[19,29]$. As an endogenous vasodilator and inhibitor of leukocyte adhesion and platelet aggregation, $\mathrm{PGI}_{2}$ acts mainly on the membrane-bound IP receptor [9] and signals by increasing the intracellular cyclic AMP (cAMP) level $[4,9,19,31]$, which leads to the activation of protein kinase $\mathrm{A}$ (PKA) and further phosphorylation of related proteins that exert a variety of biologic functions $[5$, $12,20,21] . \mathrm{PGI}_{2}$ can also bind to endogenous peroxisome proliferator-activated receptors (PPARs) and regulate the transcription of target genes $[6,40]$. NSAIDs that inhibit COX and thus prostaglandin production have been reported to increase patient's susceptibility to AKI [3, 10, 34, 35]. It has been reported that deletion of PGIS is associated with ischemic renal disorders, including nephrosclerosis and renal infarction [45]. Furthermore, in a study of rats, $\mathrm{PGI}_{2}$ protected the kidney from post-ischemic acute injury, although the mechanism is incompletely characterized [15]. These findings suggest that 
$\mathrm{PGI}_{2}$ plays an important role in maintaining renal blood flow and protecting the kidney from acute injury.

Therefore, the present study was designed to test the hypothesis that $\mathrm{PGIS} / \mathrm{PGI}_{2}$ pathway is responsible for maintaining renal homeostasis during ischemic reperfusion and protecting the kidney from AKI. This study may shed light on the mechanism underlying AKI and the therapeutic potential of the $\mathrm{PGI}_{2}$ pathway during I/RI.

\section{Materials and methods}

\section{Animals}

All animal studies were approved by the Institutional Animal Care and Use Committee of Fudan University. Wild-type (WT) C57BL/6 mice were purchased from Biomodel Organism (Shanghai, China). Mice were housed at a constant temperature and humidity room in the animal facility of Fudan University Medical Animal Center with a 12:12-h light-dark cycle and allowed free access to standard rodent chow and water.

The Cre/loxP and Flp/FRT recombination system was used to generate PGIS-floxed mouse line. The mouse genomic PGIS gene sequence was obtained from the UCSC Genome Browser. The targeting vector included a 4-kb $5^{\prime}$ homogenous arm, a reversed sequence including a splicing acceptor (SA) and an IRES (internal ribosome entrance site) tagged with EGFP (enhanced green fluorescence protein) and flanked by two reverse loxP sequence, a PGK-Neo selection cassette flanked by FRT, and a $2 \mathrm{~kb} 3^{\prime}$ homogenous arm. The IRESEGFP cDNA in the targeting construct allows for detecting where the floxed PGIS is expressed in mice carrying the transgene. The target vector was transfected into embryonic stem cells following established protocols [39]. Neomycin-resistant embryonic cell clones were screened by Southern blot, and two correctly targeted clones were identified (Fig. 1b). Two target clones (1C11 and 3D8) were picked for blastocyst injection. Germline transmission of the transgene was obtained from the $1 \mathrm{C} 11$ line. Genotyping was achieved through PCR of tail DNA with primers: P1 5'- CTGTCCCTATCTAA ACCTCACC-3', P2 5'-TAGAGCGGCCATCATAACT-3', P3 5'-GCCAAGCATTCGTAAAGCCC-3'. PCR was performed under the following conditions: denaturation at $95{ }^{\circ} \mathrm{C}$ for $3 \mathrm{~min}$; 35 cycles of $94{ }^{\circ} \mathrm{C}$ for $30 \mathrm{~s}, 58{ }^{\circ} \mathrm{C}$ for $1 \mathrm{~min}$, and $72{ }^{\circ} \mathrm{C}$ for $1 \mathrm{~min}$; and $72{ }^{\circ} \mathrm{C}$ for $5 \mathrm{~min}$. Primers P1 and P3 amplify an 857-bp wild-type allele fragment, and primers P1 and P2 amplify a 577-bp floxed allele fragment.

Mice with PGIS gene deletion were obtained by crossing the floxed PGIS mouse with a universal Cre mouse (the EIIACre mouse on the B6 background). Most of the homozygous PGIS knockout mice (PGIS ${ }^{-1}$ ) experienced embryonic lethality. The heterozygous $\left(\mathrm{PGIS}^{+/-}\right.$) mice were further bred with
WT C57BL/6 mice to expand the heterozygous PGIS knockout mice $\left(\mathrm{PGIS}^{+/-}\right.$) and WT littermates $\left(\mathrm{PGIS}^{+/+}\right.$). Genotyping was achieved with primers P4 5'-ACAGGGTTTCATCC TCAATT-3', P5 5'- GTCCTTATCATCGTCGTCTTT-3', which amplified a 900-bp knockout allele fragment.

The endothelial-specific PGIS-deficient mouse line was generated by mating the PGIS ${ }^{\mathrm{fl} / \mathrm{fl}}$ mice with the endothelial Cre TEK-CRE mouse line. Mice with both floxed PGIS alleles and the TEK-CRE transgene were generated (TEK-CRE PGIS $^{\mathrm{fl} / \mathrm{fl}}$ ). TEK-CRE PGIS ${ }^{\mathrm{fl} / \mathrm{fl}}$ mice were then backcrossed to the PGIS ${ }^{\mathrm{f} / / \mathrm{ll}}$ mice to generate both deletable and nondeletable littermates.

A smooth muscle cell-specific PGIS-deficient mouse line was generated by mating the PGIS ${ }^{\mathrm{f} / \mathrm{fl}}$ mice with the SMMHCiCRE mouse line. Mice with both floxed PGIS alleles and the SMMHC-iCRE transgene were generated (SMMHC-iCRE $\mathrm{PGIS}^{\mathrm{fl} / \mathrm{fl}}$ ). SMMHC-iCRE PGIS ${ }^{\mathrm{fl} / \mathrm{fl}}$ mice were then backcrossed to the PGIS ${ }^{\mathrm{fl} / \mathrm{fl}}$ mice to generate both deletable and nondeletable littermates.

\section{Experimental model of AKI and drug treatment}

Warm ischemia-reperfusion surgery was performed on 8- to 10-week-old male C57BL/6 mice. Mice were subjected to flank incisions. Ischemia was induced after right-sided uninephrectomy by clipping the pedicles of the remaining left kidney for $25 \mathrm{~min}$. Reperfusion was confirmed visually. The color of the kidney turned from dark purple to pink. Sham surgery was performed in a similar manner, except for clamping of the renal vessels. Iloprost $(50 \mathrm{mg} / \mathrm{kg}$ body wt) or an equivalent amount of PBS was administered $30 \mathrm{~min}$ before the surgery by intraperitoneal injection. In the nephrotoxic model, folic acid was dissolved in $0.2 \mathrm{ml}$ of $0.3 \mathrm{mM}$ sodium bicarbonate $\left(\mathrm{NaHCO}_{3}\right)$ and administered intraperitoneally at a concentration of $250 \mathrm{mg} / \mathrm{kg} / \mathrm{wt}$. To collect blood and tissue samples, mice were anesthetized with chloral hydrate $(400 \mathrm{mg} / \mathrm{kg}$, intraperitoneal injection).

\section{Renal blood flow evaluation}

Red fluorescent $15 \mu \mathrm{m}$ FluoSpheres (Molecular Probes) were used. Fifty microliters of the microsphere mixture was injected into the left atrium of live mice after IR surgery.

\section{In vivo imaging system}

Mice were anesthetized with 5\% chloral hydrate. The abdomen was opened to fully expose the kidney. In vivo images were acquired with using an In Vivo Imaging System (NightOWL LB 983, Berthold Technologies, Germany). 
a
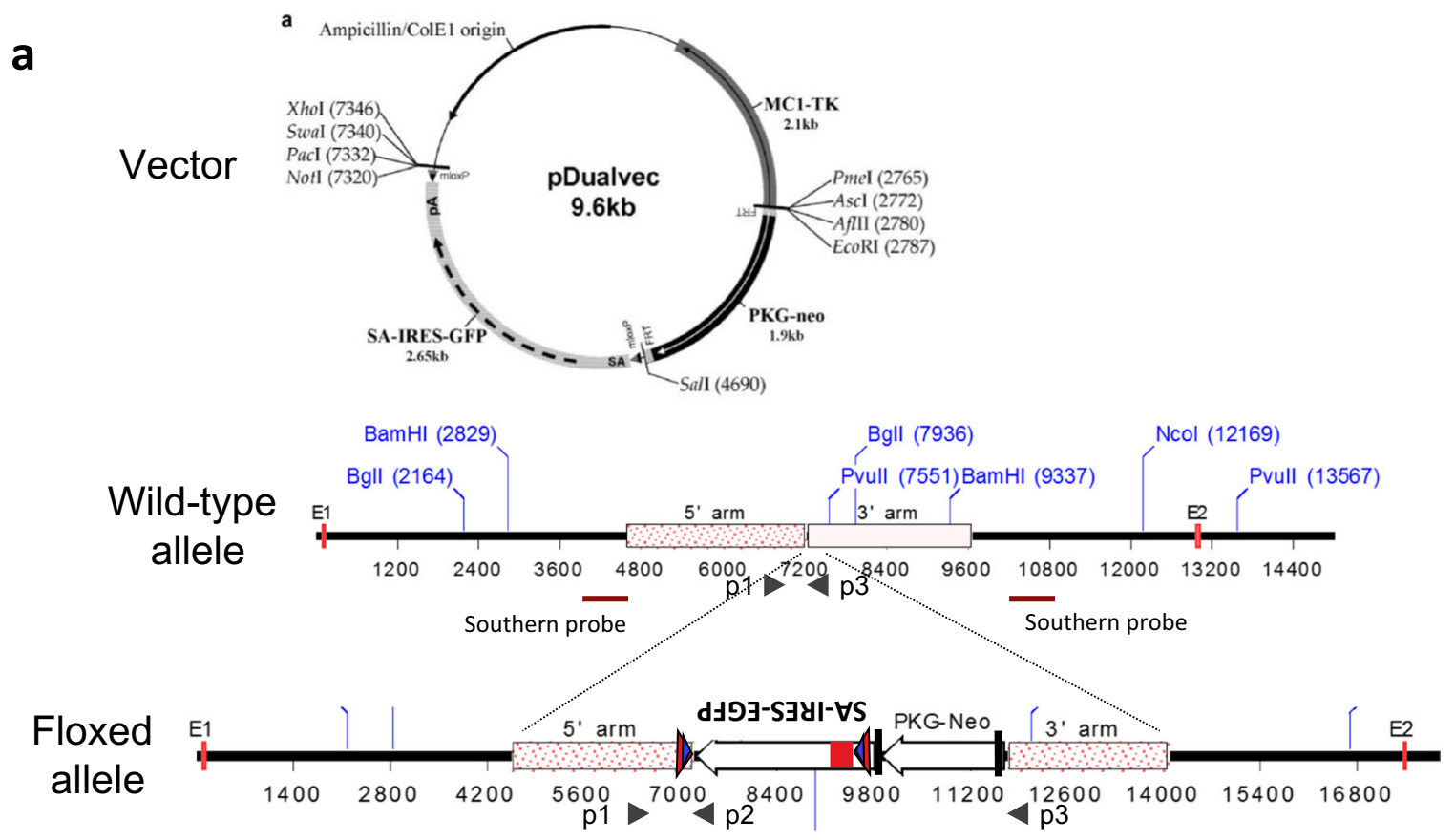

\section{Konckout allele}
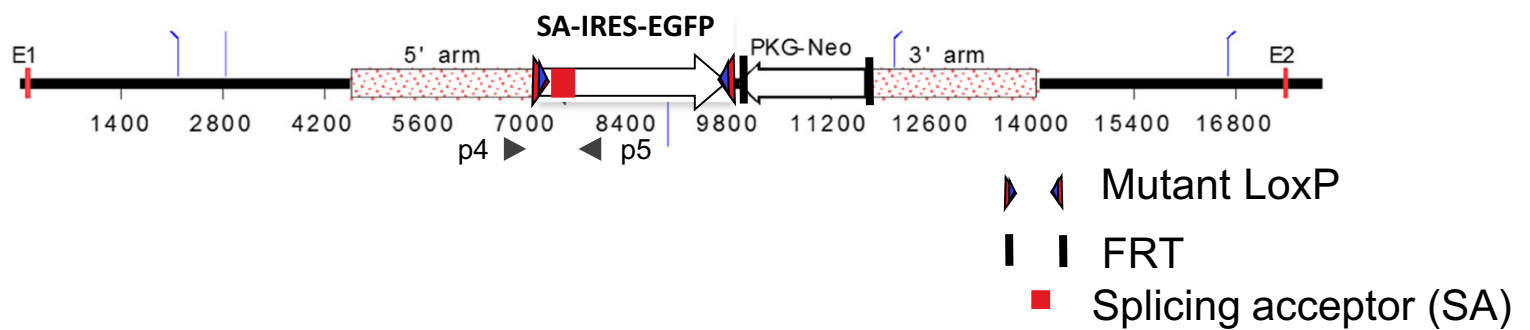

Fig. 1 Generation and confirmation of PGIS-floxed mice. a Targeting strategy. The targeting construct has a 4-kb 5' homogenous arm, a reversed sequence including an SA and an IRES-EGFP reporter flanked by two reverse loxP sequence, a PGK-Neo selection cassette flanked by FRT, and a 2-kb 3' homogenous arm. b Southern blot showed two targeted ES cell clones that give expected hybridization patterns. The $3^{\prime}$ probe indicated in a was used to confirm that the correct target was obtained. c Identification of PGIS-floxed mice by PCR. d

\section{Quantitation of fluorescence}

The animals were sacrificed, and the kidneys were removed for fluorescence quantification after digestion and filtration, according to the manufacturer's instructions. The intensity of the fluorescence signal was determined with an EnSpire luminescence spectrophotometer (Perkin-Elmer, Beaconsfield, UK) equipped with a 96-well microplate reader. The fluorescence intensity was measured at the optimal excitationemission wavelengths of red dye (570 and $598 \mathrm{~nm}$ ).

\section{Prostaglandin production assessment}

The production of $\mathrm{PGI}_{2}$ was assessed by measuring 6-Keto PGF $_{1 \alpha}$ using an ELISA Kit (No. 515211; Cayman Chemical
Determination of conventional knockout E16.5 embryos' genotypes by PCR. PGIS production in the body of E16.5 embryos was analyzed by real-time PCR (e) and Western blot (f). A total of 11 mice were included ( $n=4$ in the WT group; $n=4$ in the $\mathrm{PGIS}^{+/-}$group, and $n=3$ in the PGIS $^{-/-}$group). The data are expressed as the mean \pm SEM and were analyzed using one-way ANOVA among multiple groups followed by Scheffe post hoc testing. ${ }^{* * *} P<0.001$. WT, wild-type; KO, knockout

Company, Ann Arbor, MI) according to the manufacturer's instructions. Thromboxane $\mathrm{A}_{2}$ was assessed by measuring thromboxane $\mathrm{B}_{2}$ using an ELISA Kit (No. 501020; Cayman Chemical). $\mathrm{PGE}_{2}$ was also measured with an ELISA Kit (514,010; Cayman Chemical).

\section{Measurement of blood pressure}

Mice were restrained in a mouse pocket and maintained at $37{ }^{\circ} \mathrm{C}$. Each mouse had their blood pressure continuously measured 10 times per day for a week by the tail-cuff method with a noninvasive automatic blood pressure analyzer (BP2000 Blood Pressure Analysis System, Visitech Systems, USA), and the mean results were used. 
b

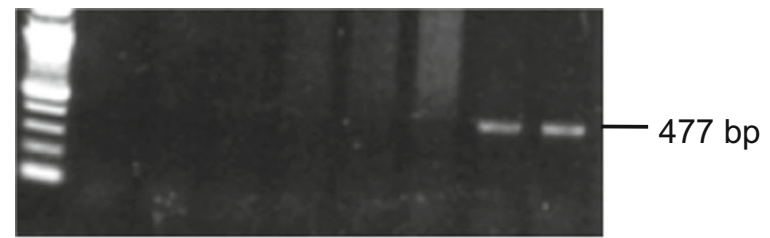

C

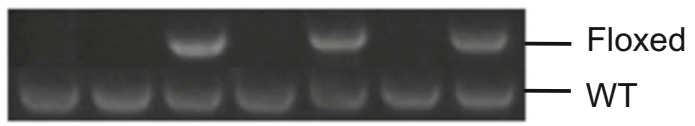

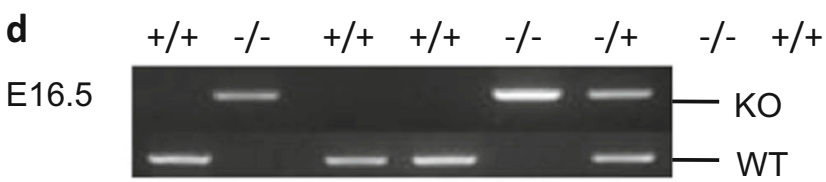

e

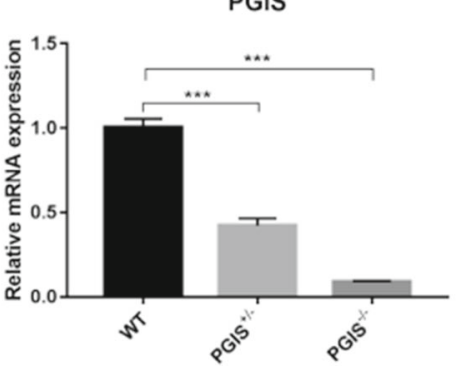

f

PGIS

GAPDH $-/-\quad-/-\quad+/-\quad+/-\quad+/+\quad+/+$

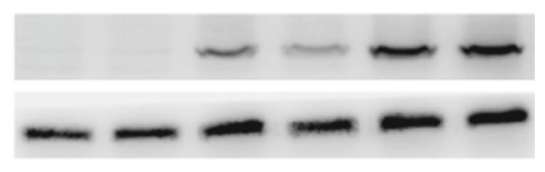

Fig. 1 continued.

\section{Renal function evaluation}

Renal function was evaluated by blood urea nitrogen (BUN). BUN was measured using a UREA KIT (liquid; UV-GLDH method; Shanghai Kehua Bioengineering Co., Ltd.) according to the manufacturer's instructions.

\section{Kidney histology}

Kidney samples were fixed in $4 \%$ paraformaldehyde, and paraffin-embedded, 2- $\mu \mathrm{m}$ sections were stained with periodic acidSchiff. Over six low-power fields of each section were reviewed and scored for tubular injury in a single-blind fashion using a modified one to four scoring system, as described previously [1].

\section{Immunofluorescence}

Paraformaldehyde-fixed, paraffin-embedded, 2 - $\mu$ m-thick sections were deparaffinized in xylene and rehydrated in a graded alcohol series. To retrieve the antigen, sections were heated in citrate buffer ( $\mathrm{pH} 6.0$ ) for $15 \mathrm{~min}$ at $120^{\circ} \mathrm{C}$ by means of an autoclave. Sections were then blocked with $5 \%$ BSA and incubated overnight at $4{ }^{\circ} \mathrm{C}$ with the following primary antibodies: mouse anti-PGIS (1:100; Cayman Chemical) and rat antiCD34 (1:200; Abcam, Cambridge, UK). For fluorescent visualization of the bound primary antibodies, sections were further incubated with the appropriate $\mathrm{Cy} 3$-conjugated or FITCconjugated secondary antibodies (1:200; Jackson ImmunoResearch Laboratories) for $1 \mathrm{~h}$ at room temperature.

\section{Electron microscopy}

Kidney tissues were fixed in $2.5 \%$ glutaraldehyde and $2.5 \%$ paraformaldehyde in phosphate buffer. After a standard embedding procedure, the peritubular capillaries were examined and photographed under a transmission electron microscope.

\section{TUNEL assay}

Apoptotic cells were detected by TUNEL assay (G3250; Promega, Fitchburg, WI) according to the manufacturer's instruction, and the number of TUNEL-positive cells in five sections per kidney was quantified. DAPI was used as a counterstain.

\section{Real-time PCR}

Total RNA was extracted from the kidney tissue using TRIzol Reagent (Invitrogen, Carlsbad, CA), and $1 \mu \mathrm{g}$ RNA was reverse transcribed using oligo $\mathrm{dT}$ as the primer according to the manufacturer's instructions (RR037; Takara Bio, Dalian, China). Real-time PCR was performed using the SYBR Green Premix Kit (RR820; Takara Bio, Dalian, China). The expression level of genes of interest was calculated with a comparative method $\left(2^{-\mathrm{DDCT}}\right)$ using $\beta$-actin as an internal control. The following primers were obtained from the primer bank: PGIS, forward 5'-CTGGTTGGGGTATGCCTTGG and reverse 5'- TCATCACTGGGGCTGTAATGT; $\beta$-actin, 
a

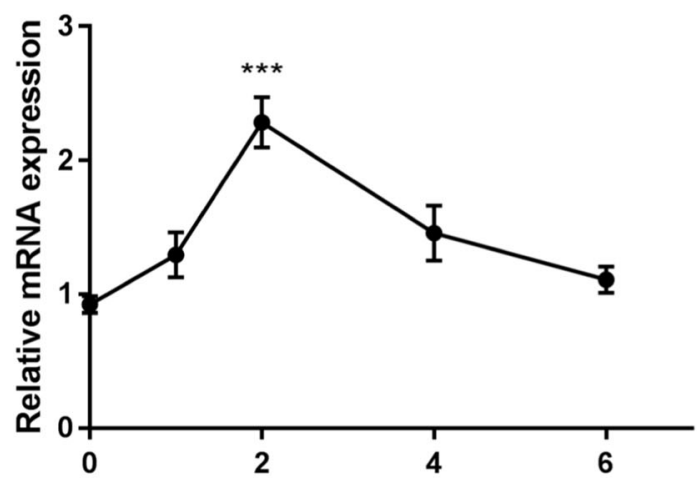

C

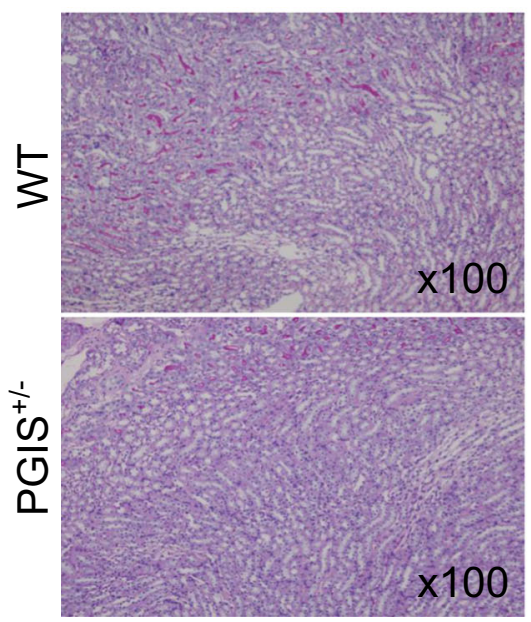

Fig. 2 The PGIS-deficient kidney is susceptible to AKI. WT and PGIS ${ }^{+/}$ mice were subjected to right uninephrectomy and sham surgery or $25 \mathrm{~min}$ of left renal ischemia. a The relative mRNA expression of PGIS was measured at the indicated times. A total of 20 mice were included $(n=4$ per time point). b BUN concentrations were measured at $48 \mathrm{~h}$ after ischemia. A total of 10 mice were included $(n=4$ in the WT group and

forward 5'- GGCTGTATTCCCCTCCATCG and reverse 5'CCAGTTGGTAACAATGCCATGT.

\section{Western blotting}

Protein was extracted from frozen kidney tissues using RIPA lysis buffer (P0013B; Beyotime, Nantong, China) with a phosphatase inhibitor tablet (Roche Diagnostics GmbH, Mannheim, Germany), a proteinase inhibitor cocktail tablet (Roche), and $100 \mathrm{mM}$ phenylmethanesulfonyl fluoride (ST506; Beyotime), and the ratio of the listed chemicals to the RIPA lysis buffer was $1: 100$. Protein concentration was determined using the Bradford protein assay (P0011; Beyotime). After the proteins were separated via SDS-PAGE, they were transferred electrophoretically to PVDF membranes (Millipore, Billerica, MA) and blocked with $5 \%$ nonfat milk or BSA. Then, immunoblotting was performed using specific antibodies overnight at $4{ }^{\circ} \mathrm{C}$ : rabbit b

I/RI-48h

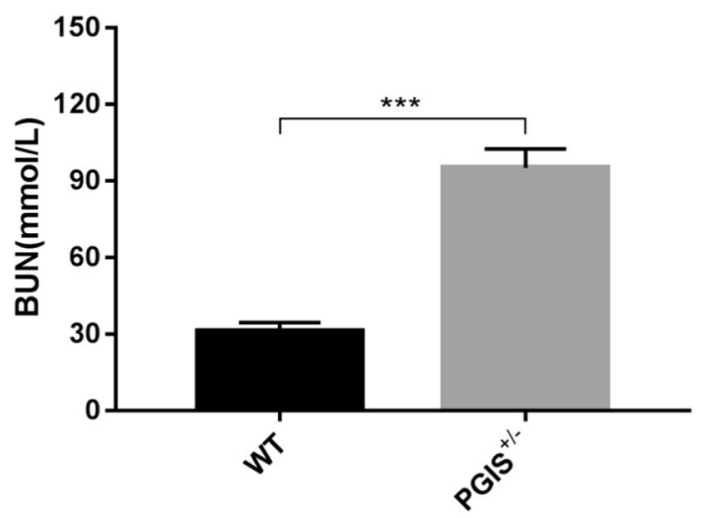

I/R-|48h

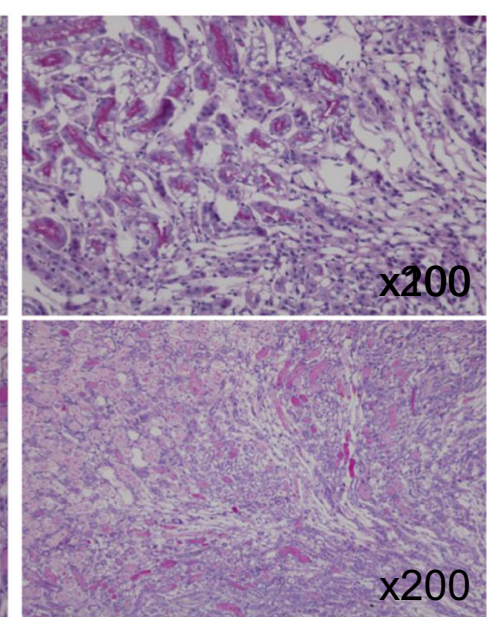

$n=6$ in the $\mathrm{PGIS}^{+/-}$group). c Renal tubular injury is indicated by representative periodic acid-Schiff staining of kidney sections at both low and high magnification. The data are expressed as the mean $\pm \mathrm{SEM}$ and were analyzed by Student's unpaired $t$ test between two groups and one-way ANOVA among multiple groups followed by Dunnett's post hoc testing. $* * * P<0.001 ; \mathrm{WT}$, wild type; $\mathrm{CON}$, control

anti-PGIS (1:500; Abcam), anti-PKA (1:1000; CST, Danvers, MA), anti-P-PKA (1:1000; CST), anti- $\beta$-actin (1:5000; CST), and anti- $\alpha$-tubulin (1:8000; Abcam). Then, the membranes were incubated with horseradish peroxidase-conjugated anti-rabbit or anti-mouse Ig for $1 \mathrm{~h}$ at room temperature. Antibody labeling on the Western blots was visualized using a chemiluminescence reagent (WBKLS0100; Millipore) with GE ImageQuant LAS 4000. Densitometry analysis was performed using ImageJ software.

\section{Statistical analyses}

All values are expressed as the mean \pm SEM. Statistical comparisons were made by Student's unpaired $t$ test or one-way ANOVA with post hoc analysis. GraphPad Prism 7 and SPSS 24 software were used for all calculations. A two-sided $P$ value of less than 0.05 was considered significant. 
a

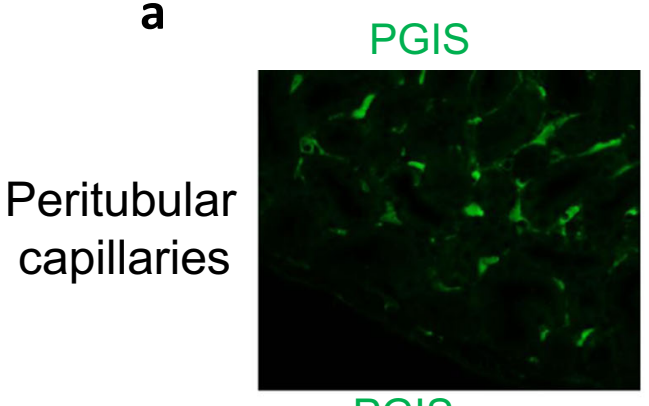

PGIS

Glomeruli

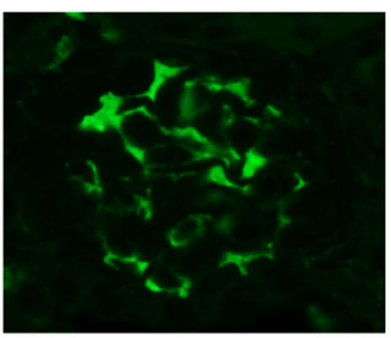

CD34

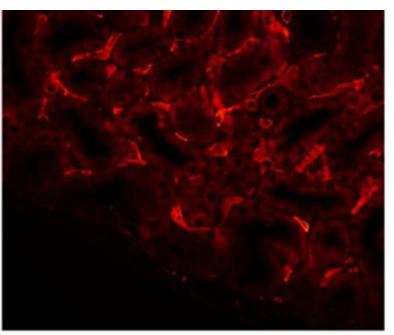

CD34

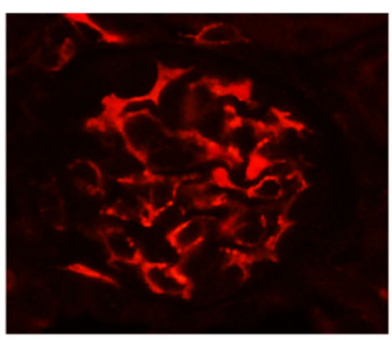

C

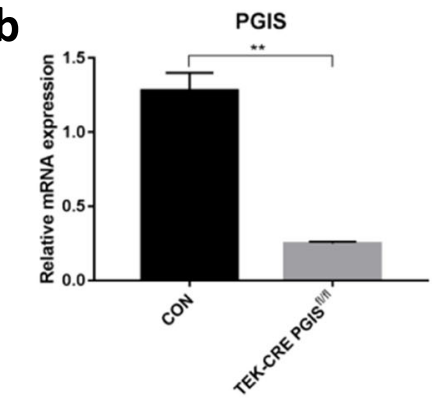

C

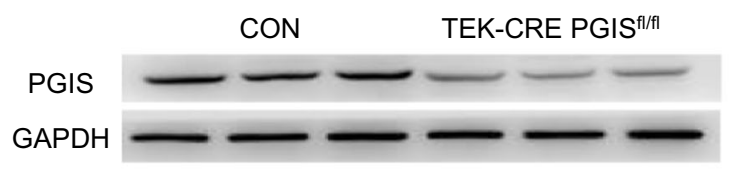

d

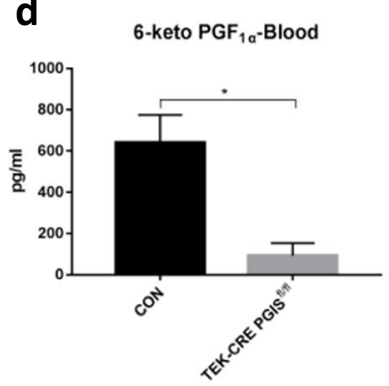

e

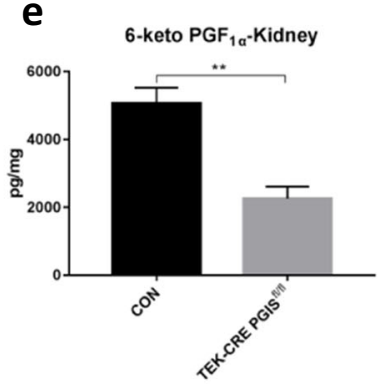

Fig. 3 Prostanoid production in endothelial-specific PGIS-deficient mice. a Costaining of PGIS with endothelial cell marker CD34 in wild-type kidney sections. b Relative mRNA expression level of PGIS in the kidneys of control $(\mathrm{CON})$ and endothelial-specific PGIS-deficient $\left(\right.$ TEK-CRE PGIS $\left.{ }^{\mathrm{fl} / \mathrm{fl}}\right)$ mice $(P=0.001)$. c Representative Western blot image of PGIS protein expression in the kidney. GAPDH was used as a

\section{Results}

\section{Generation of PGIS-floxed mice}

To examine the role of PGIS and $\mathrm{PGI}_{2}$ during kidney I/RI, we developed a PGIS-floxed mouse line. The SA-IRES-EGFP fragment and a PGK-Neo selection cassette were inserted between PGIS exon 1 and exon 2 to inactivate the PGIS gene

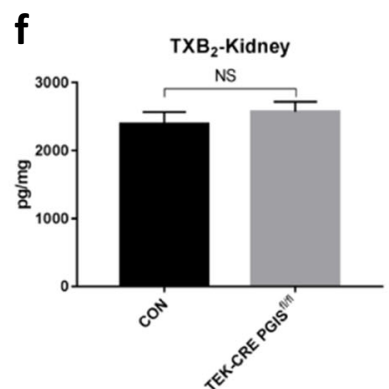

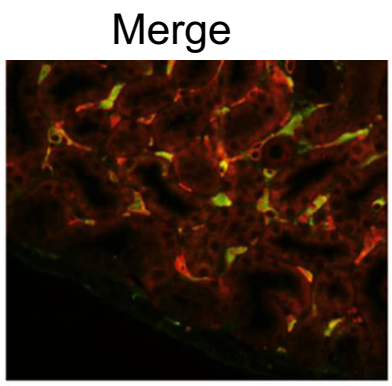

Merge

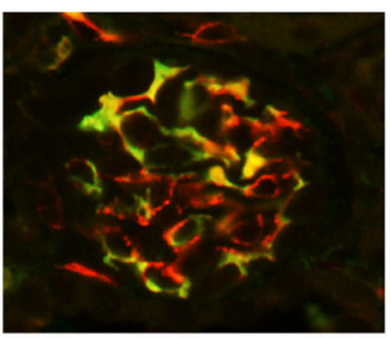

PGIS expression
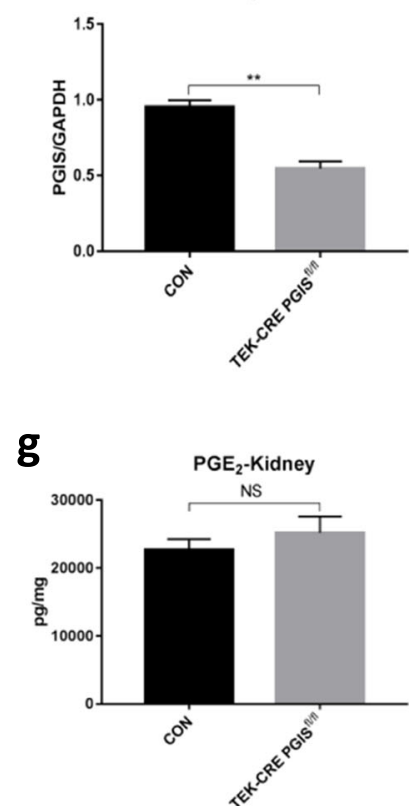

loading control. Band density was measured using Image J software $(P=$ 0.003). d 6-Keto $\mathrm{PGF}_{1 \alpha}$ level in the plasma $(P=0.020)$. 6-Keto $\mathrm{PGF}_{1 \alpha}$ (e) $(P=0.001), \mathrm{TXB}_{2}(\mathbf{f})$, and $\mathrm{PGE}_{2}(\mathbf{g})$ levels in the kidney. The experiments were repeated twice. A total of 12 mice were included $(n=6$ per group). The data are expressed as the mean \pm SEM and were analyzed by Student's unpaired $t$ test. $* P<0.05 ; * * P<0.01$; NS, not significant

(Fig. 1a). Neo-resistant embryonic cell clones were screened by Southern blot (Fig. 1b). The mouse genotype was identified by PCR (Fig. 1c). To confirm whether the PGIS-floxed mice were successfully generated, we mated the PGIS ${ }^{\mathrm{fl} /+}$ mouse with the EIIA-cre mouse to produce conventional PGIS knockouts. The homozygous PGIS knockout mice were embryonic lethal after E16.5 days. We analyzed the expression of PGIS mRNA and PGIS protein in the E16.5 embryos 
Fig. 4 Morphology of the kidneys of wild-type and TEKCRE PGIS ${ }^{\mathrm{fl} / \mathrm{fl}}$ mice (periodic acidSchiff stain)

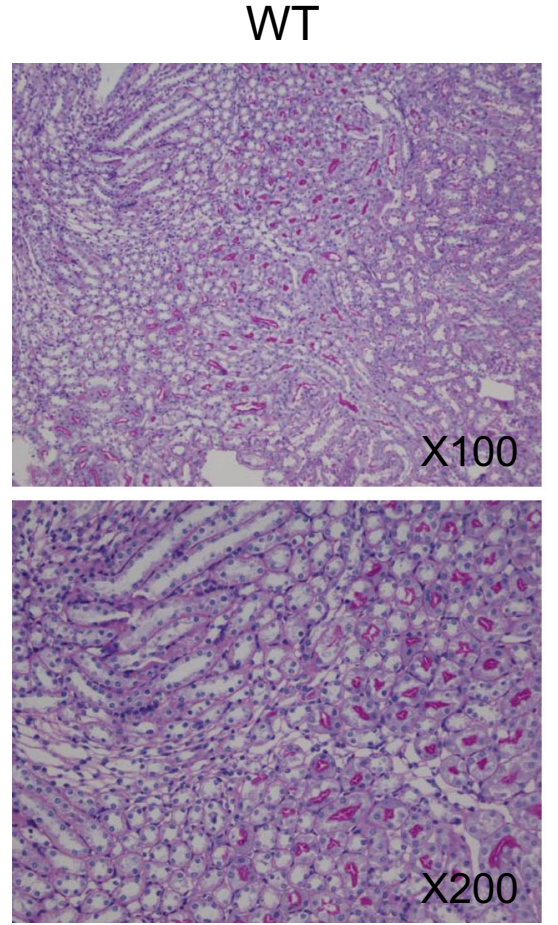

TEK-CRE PGISfl/fl
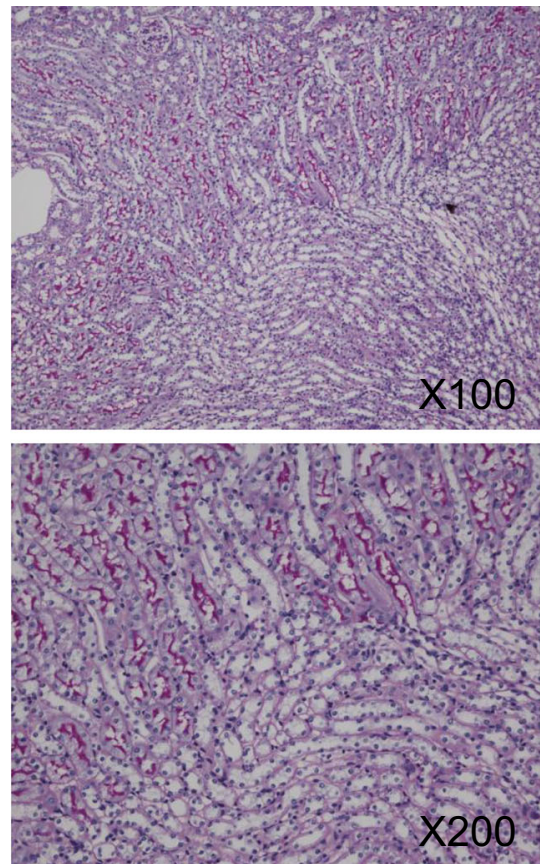

by real-time PCR and Western blot, respectively (Fig. 1d-f). The expression of PGIS mRNA was significantly reduced in heterozygous embryos and was absent in homozygous embryos. Likewise, the PGIS protein was undetectable in homozygous embryos, indicating that the PGIS-floxed mice were successfully established.

\section{PGIS deficiency aggravates I/R-induced AKI}

The PGIS expression significantly increased at $48 \mathrm{~h}$ after I/R (Fig. 2a). To determine the role of PGIS in kidney injury, studies were performed in the PGIS heterozygous mice. Deletion of one allele of the PGIS gene significantly aggravated renal damage compared with wild-type littermates at $48 \mathrm{~h}$ after ischemia, resulting in a higher BUN levels and more severe tubular injury (Fig. 2b, c).

Table 1 Systolic blood pressure (BP) and the heart rate of wild-type and TEK-CRE PGIS ${ }^{\mathrm{fl} / \mathrm{fl}}$ mice. The results are the means \pm SEM and were analyzed by Student's unpaired $t$ test. A total of 20 mice were included ( $n=8$ in the wild-type group and $n=12$ in the TEK-CRE PGIS ${ }^{\mathrm{fl} / \mathrm{fl}}$ group)

Blood pressure and heart rate of wild-type and TEK-CRE PGIS ${ }^{\mathrm{fl} / \mathrm{fl}}$ mice

\begin{tabular}{llc}
\hline & Wild type $(n=8)$ & TEK-CRE PGIS $^{\mathrm{fl} / \mathrm{fl}}(n=12)$ \\
\hline Systolic BP, mmHg & $106 \pm 2$ & $99 \pm 3$ \\
Heart rate, bpm & $454 \pm 15$ & $426 \pm 7$ \\
\hline
\end{tabular}

\section{Role of endothelial PGIS in AKI}

By immunofluorescence, PGIS was found colocalized with CD34, an endothelial cell marker. PGIS was expressed in the cytoplasm of endothelial cells both in the peritubular capillaries and the glomeruli (Fig. 3a). To determine the specific role of endothelial PGIS and $\mathrm{PGI}_{2}$ during renal I/RI, we generated a mouse that was deficient in PGIS specifically within the endothelium by mating the floxed PGIS mouse with an endothelial Cre mouse, the TEK-CRE mouse. PGIS expression was significantly decreased both at the mRNA and protein levels in endothelial-specific PGIS-deficient mice (TEK-CRE PGIS ${ }^{\mathrm{fl} / \mathrm{fl}}$ ) compared with control mice (Fig. 3b, c). The production of $\mathrm{PGI}_{2}$ was also significantly reduced both in the blood and kidney compared with the control group, as assessed by 6-Keto $\mathrm{PGF}_{1 \alpha}$, a stable metabolite of $\mathrm{PGI}_{2}$ (Fig. 3d, e). We also measured $\mathrm{TXB}_{2}$, a stable metabolite of $\mathrm{TXA}_{2}$, and $\mathrm{PGE}_{2}$ in kidneys (Fig. 3f, g). Deleting the PGIS gene in endothelial cells did not influence the expression of other genes in the prostaglandin family.

No developmental abnormalities were observed in the kidneys of TEK-CRE PGIS ${ }^{\mathrm{fl} / \mathrm{fl}}$ mice (Fig. 4). The blood pressure and heart rates were comparable between wild-type mice and TEK-CRE PGIS ${ }^{\mathrm{fl} / \mathrm{fl}}$ mice (Table 1). Following ischemia and reperfusion, the TEK-CRE PGIS ${ }^{\mathrm{f} / \mathrm{fl}}$ mice had higher BUN levels than control mice (Fig. 5a). The endothelial-specific PGIS knockout also abolished the increase of PGIS expression and $\mathrm{PGI}_{2}$ production after ischemia and reperfusion (Fig. 5b, c). Deletion of the PGIS gene specifically in smooth muscle cells did not worsen the kidney injury compared with wild-type littermates after ischemia and reperfusion (Fig. 5d). 
a

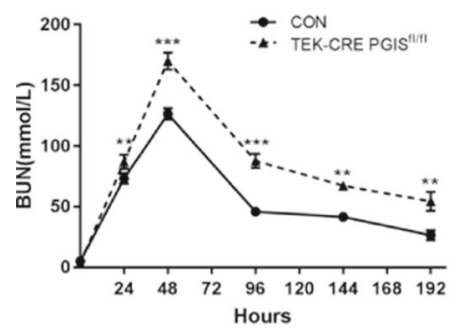

b<smiles>CC(N)=O</smiles>
B-actin

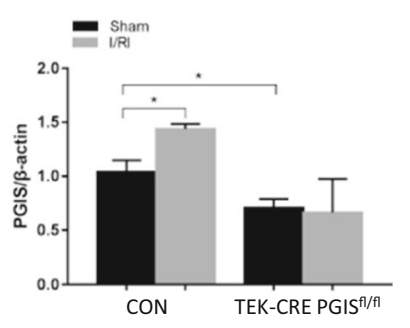

c

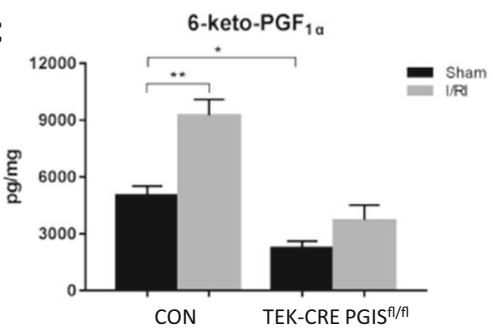

d

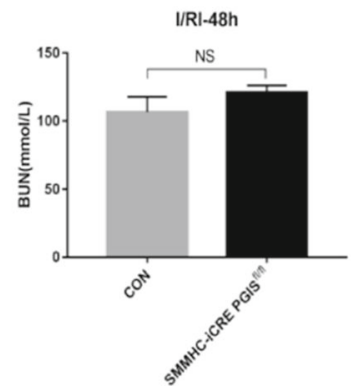

Fig. 5 Endothelial PGIS protects the kidney from AKI. The control mice, TEK-CRE PGIS ${ }^{\mathrm{fl} / \mathrm{fl}}$ mice, and SMMHC-iCRE PGIS ${ }^{\mathrm{fl} / \mathrm{fl}}$ mice were subjected to either renal ischemia or a sham operation. a BUN concentrations at the indicated times. A total of eight mice were included ( $n=4$ per group). b Representative Western blot images of PGIS protein expression in the kidney (in the control group, $P=0.033$ Sham vs. I/RI). $\beta$-Actin was used as a loading control. Band density was measured using ImageJ software. $\mathbf{c}$ The production of 6-Keto $\mathrm{PGF}_{1 \alpha}$ in the kidneys (in the control group, $P=0.001$ Sham vs. I/RI). For b, c, 24 mice were included (CON mice: $n=7$ in the Sham group, $n=6$ in the I/RI group; TEK-CRE
PGIS ${ }^{\mathrm{fl} / \mathrm{fl}}$ mice: $n=5$ in the Sham group, $n=6$ in the I/RI group). $\mathbf{d} \mathrm{BUN}$ concentrations were measured at $48 \mathrm{~h}$ after ischemia. A total of eight mice were included ( $n=4$ per group). The data are expressed as the mean \pm SEM and were analyzed by Student's unpaired $t$ test between two groups and one-way ANOVA among multiple groups followed by Scheffe post hoc testing. For a, the data were analyzed by Student's unpaired $t$ test followed by Bonferroni correction (a two-sided $P$ value less than 0.01 was considered significant). $* P<0.05 ; * * P<0.01 ; * * * P<0.001$; NS, not significant
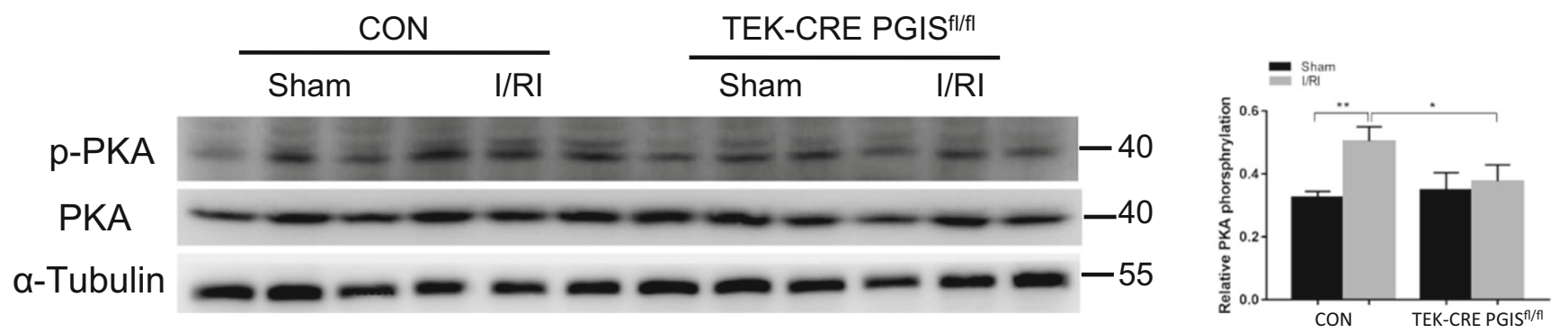

Fig. 6 Representative Western blot images of phosphorylated protein kinase A (p-PKA) (in the control group, $P=0.006$ Sham vs. I/RI). $\alpha$ Tubulin was used as a loading control. Band density was measured using Image J software. A total of 24 mice were included (CON mice: $n=7$ in the Sham group, $n=6$ in the I/RI group; TEK-CRE PGIS ${ }^{\mathrm{fl} / \mathrm{fl}}$ mice: $n=5$ in the Sham group, $n=6$ in the I/RI group). The data are expressed as the mean \pm SEM and were analyzed by one-way ANOVA among multiple groups followed by Scheffe post hoc testing. $* P<0.05 ; * * P<0.01$ 


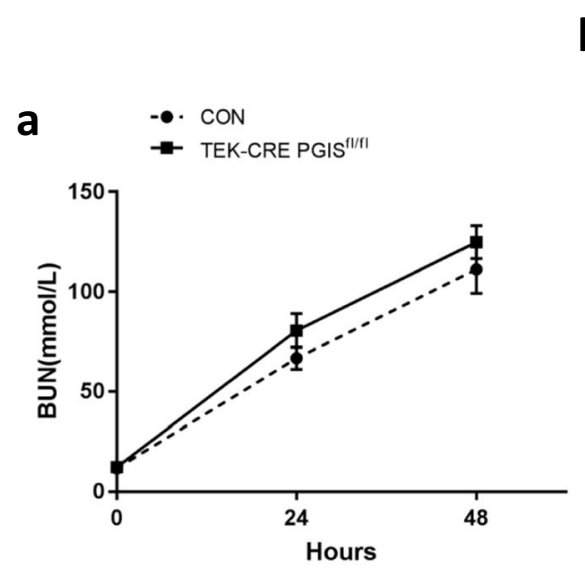

b

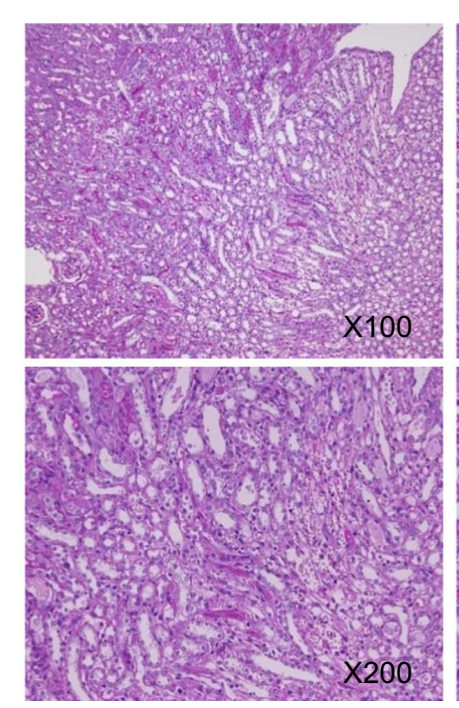

TEK-CRE PGIS $S^{\mathrm{fl} / \mathrm{fl}}$

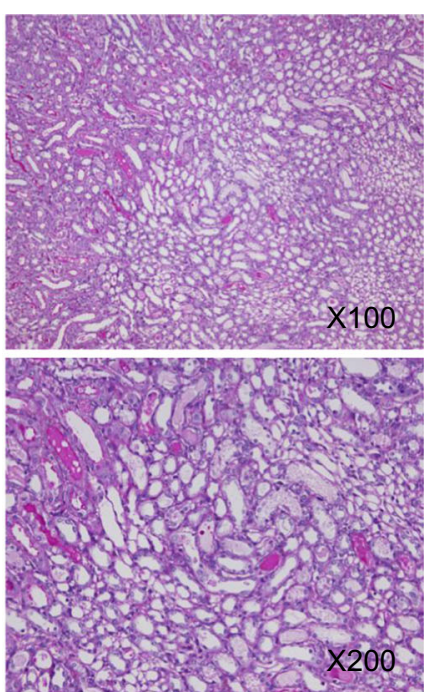

Fig. $7 \mathrm{PGI}_{2}$ has no protective effects in a folic acid-induced AKI model. a BUN concentrations at the indicated times. b Renal tubular injury as indicated by representative periodic acid-Schiff staining of kidney

\section{The $\mathrm{PGIS} / \mathrm{PGI}_{2} / \mathrm{IP}$ receptor signaling pathway is activated during $\mathbf{I} / \mathrm{R}$-induced $\mathrm{AKI}$}

The IP receptor signals mainly through the cAMP/PKA signaling pathway. Following I/R, the level of phosphorylated PKA was significantly increased in the control kidneys but not in the endothelial-specific PGIS knockout kidneys (Fig. 6), consistent with IP/PKA signaling in $\mathrm{PGI}_{2}$-associated effect on kidney injury. We then examined the role of PGIS/PGI 2 in a nephrotoxic AKI induced by folic acid. PGIS deficiency did not worsen renal damage in the folic acid model (Fig. 7).

\section{Treatment with a $\mathrm{PGI}_{2}$ analog protects the kidney from I/R injury}

We further examined whether a $\mathrm{PGI}_{2}$ analog, iloprost, can rescue the effect of knocking out PGIS. Iloprost or PBS was administered $30 \mathrm{~min}$ before the surgery. BUN measurement, histology analysis, and TUNEL staining were performed at $48 \mathrm{~h}$ after ischemia. As shown in Fig. 8, mice treated with iloprost had a significantly lower BUN and improved tubular damage compared with mice treated with PBS both in the control group and the TEK-CRE PGIS ${ }^{\mathrm{fl} / \mathrm{fl}}$ group, indicating a potential target for AKI treatment.

\section{Deletion of PGIS gene in endothelial cells reduced renal blood flow after reperfusion}

In the kidneys of TEK-CRE PGIS ${ }^{\mathrm{fl} / \mathrm{fl}}$ mice, red blood cells were readily observed in the peritubular capillaries at $24 \mathrm{~h}$ after ischemia (Fig. 9a). We then examined renal blood flow using a fluorescent microspheres technique. The fluorescent sections at $48 \mathrm{~h}$ after folic acid treatment. A total of 10 mice were included ( $n=5$ per group). The data are expressed as the mean \pm SEM and were analyzed by Student's unpaired $t$ test between two groups

intensity of the kidney was markedly less in the TEK-CRE PGIS $^{\mathrm{fl} / \mathrm{fl}}$ mice compared with the control mice (Fig. 9b, c).

\section{Discussion}

In the present study, we demonstrated that (1) I/R stimulated the expression of PGIS and $\mathrm{PGI}_{2}$; (2) global PGIS deficiency or endothelial-specific PGIS deletion exacerbated I/R-induced injuries; (3) an exogenous $\mathrm{PGI}_{2}$ analog protected the kidney from I/R-induced injury; and (4) $\mathrm{PGI}_{2}$ deficiency was associated with reduced renal blood flow following reperfusion. These results strongly suggest that endothelium-derived $\mathrm{PGI}_{2}$ plays a critical role in protecting the kidney from $\mathrm{I} / \mathrm{R}$ injury.

It is well documented that prostanoids play an important role in maintaining local homeostasis [18]. PGIS expression markedly increased following I/R injury, and PGIS deficiency significantly exacerbated kidney I/R injury. These results suggest that $\mathrm{PGIS} / \mathrm{PGI}_{2}$ is involved in the cellular response to $\mathrm{I} / \mathrm{R}$ stress and protects the kidney from injury. COX inhibitors, which are widely used anti-inflammatory drugs and pain relievers, are associated with AKI. COX-derived products include $\mathrm{PGE}_{2}, \mathrm{PGI}_{2}$, and $\mathrm{TXA}_{2}$. The present study suggests that $\mathrm{PGI}_{2}$ is an important protective factor, particularly under I/R conditions, and its inhibition may be, at least in part, responsible for COX inhibitor-induced AKI. Importantly, several studies have shown that the ability of the kidney to produce $\mathrm{PGI}_{2}$ decreases with aging $[7,33]$. Whether reduced $\mathrm{PGI}_{2}$ production in aged people contributes to their increased susceptibility to AKI remains to be investigated. 


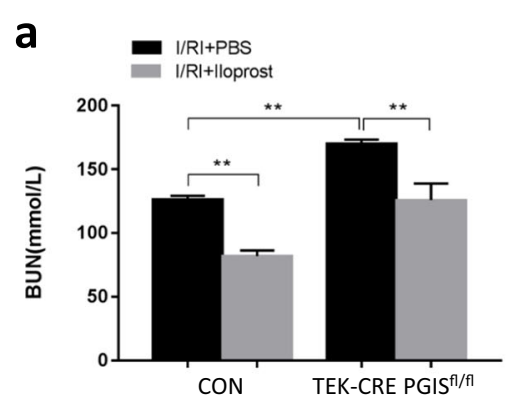

b

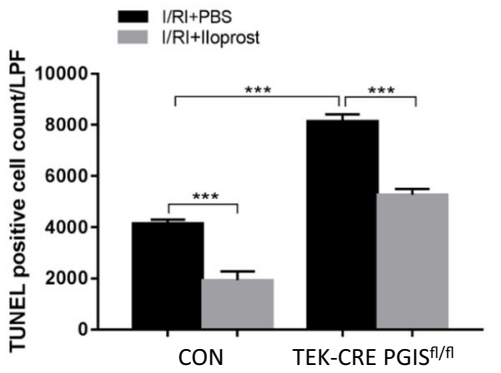

c

PBS
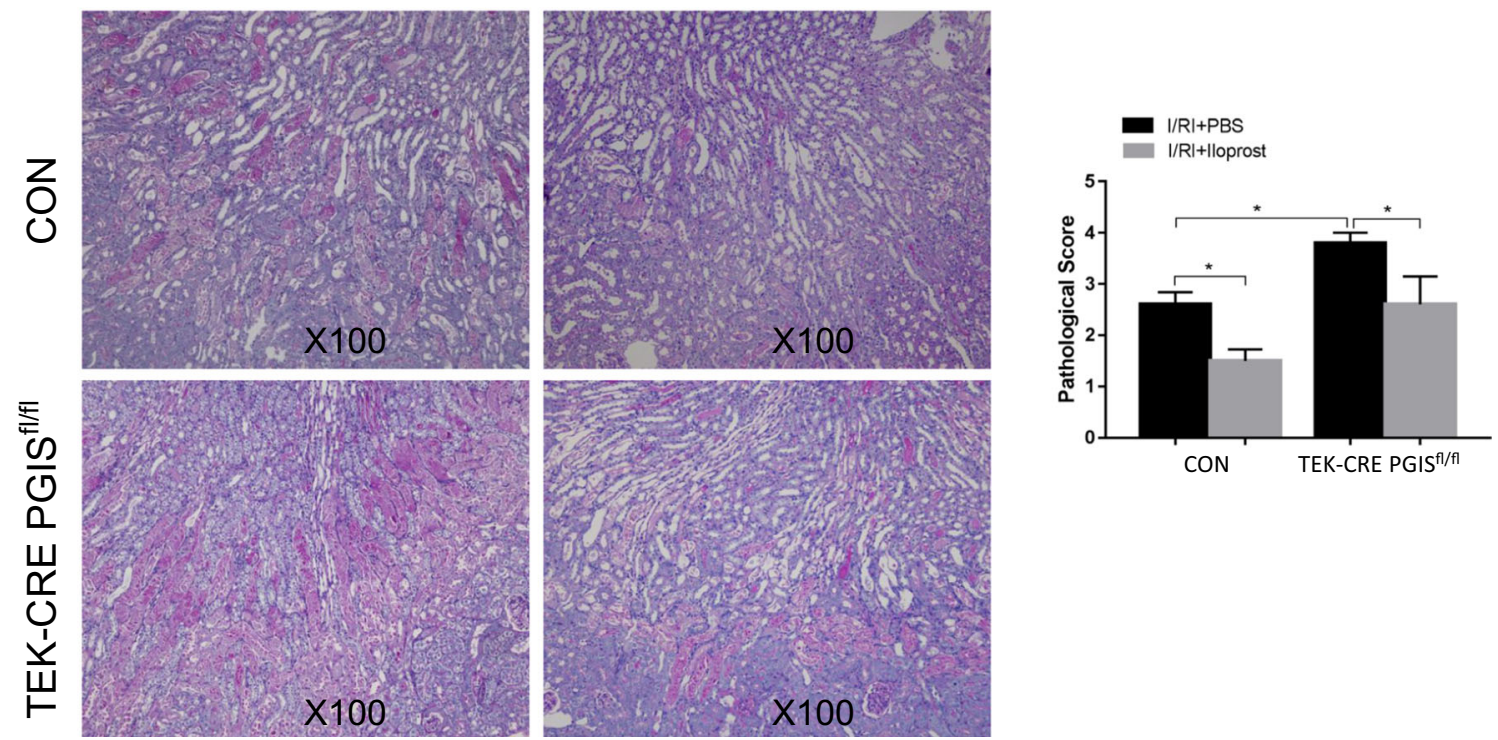

Fig. $8 \mathrm{PGI}_{2}$ protects kidneys from I/R-induced AKI. a Renal function as evaluated by serum BUN in control and TEK-CRE PGIS ${ }^{\mathrm{fl} / \mathrm{fl}}$ mice at $48 \mathrm{~h}$ after ischemia with or without treatment with the $\mathrm{PGI}_{2}$ analog, iloprost (control group: $P=0.001 \mathrm{I} / \mathrm{RI}+\mathrm{PBS}$ vs. I/RI + Iloprost; TEK-CRE PGIS ${ }^{\mathrm{fl} / \mathrm{fl}}$ group: $P=0.002 \mathrm{I} / \mathrm{RI}+\mathrm{PBS}$ vs. I/RI + Iloprost). Renal tubular injury as indicated by representative periodic acid-Schiff staining of kidney sections and evaluated based on a pathological score (control group: $P=0.026 \mathrm{I} / \mathrm{RI}+\mathrm{PBS}$ vs. $\mathrm{I} / \mathrm{RI}+$ Iloprost; TEK-CRE PGIS ${ }^{\mathrm{fl} / \mathrm{fl}}$

group: $P=0.019 \mathrm{I} / \mathrm{RI}+\mathrm{PBS}$ vs. I/RI + Iloprost) $(\mathbf{b})$ and TUNEL staining (c). A total of 24 mice were included (CON mice: $n=6$ in the I/RI + PBS group, $n=7$ in the I/RI + Iloprost group; TEK-CRE PGIS ${ }^{\mathrm{fl} / \mathrm{fl}}$ mice: $n=6$ in the I/RI + PBS group, $n=5$ in the I/RI + Iloprost group). The data are expressed as the mean \pm SEM and were analyzed by one-way ANOVA among multiple groups followed by Scheffe post hoc testing. $* P<0.05$; $* * P<0.01 ; * * * P<0.001$

For the first time, the present study shows in vivo that endothelial $\mathrm{PGI}_{2}$ plays a critical role in the cellular response to ischemic reperfusion and protects the kidney from injury using our floxed PGIS mice. By costaining PGIS with CD34, an endothelial marker, we show that PGIS is extensively expressed in the endothelial cells of the kidney. Our floxed PGIS mice allowed us to specifically explore the role of endothelial PGIS in renal I/R injury. We selectively deleted the PGIS gene in endothelial cells by crossing the floxed PGIS mice with an endothelial cell Cre mouse (TEK-CRE PGIS ${ }^{\mathrm{f} / / \mathrm{fl}}$ ). In an I/R-induced AKI model, the PGIS and $\mathrm{PGI}_{2}$ expression levels significantly increased after ischemia in the control kidneys but not in endothelial PGIS knockout kidneys. Selective deletion of endothelial PGIS markedly worsened the kidney

damage following $\mathrm{I} / \mathrm{R}$, suggesting a protective role of endothelial $\mathrm{PGI}_{2}$ in the kidney. Deletion of PGIS did not alter the production of $\mathrm{TXA}_{2}$ and $\mathrm{PGE}_{2}$, suggesting that the worsened renal damage was not caused by $\mathrm{TXA}_{2}$ or other prostanoids. Furthermore, administration of iloprost significantly attenuated the renal damage both in the control mice and endothelial PGIS knockout mice, supporting the protective role of $\mathrm{PGI}_{2}$. However, iloprost binds with equal affinity to IP and prostaglandin EP1 receptors and with lower affinity to EP3 receptors. Several studies show that high concentration of $\mathrm{PGI}_{2}$ can cause vasoconstriction under such conditions as NO or IP deficiency, and the vasoconstrictor effect of $\mathrm{PGI}_{2}$ is blocked by TP receptor antagonist $[13,26,28]$. Although these studies are important for us to understand the mechanism underlying 
a

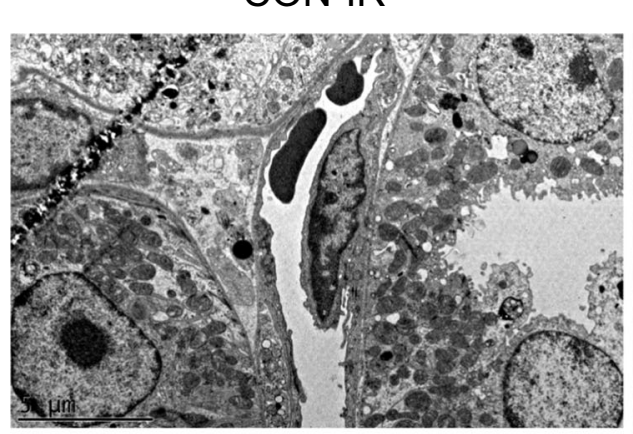

TEK-CRE PGIS $S^{f / / f I}-I R$

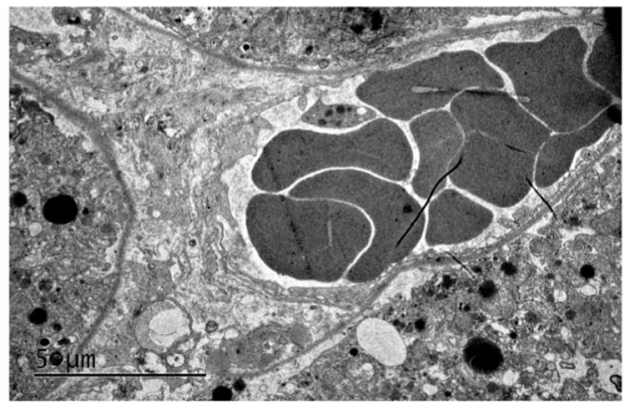

b CON-IR

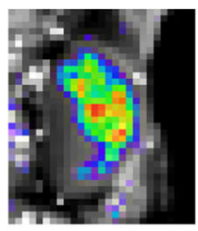

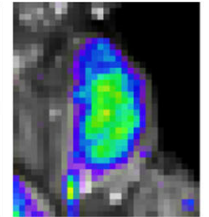

.

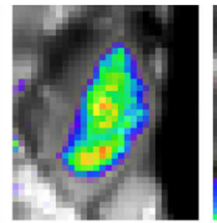

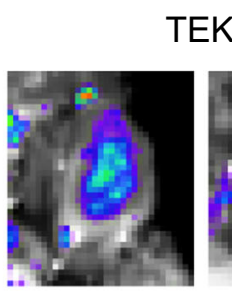

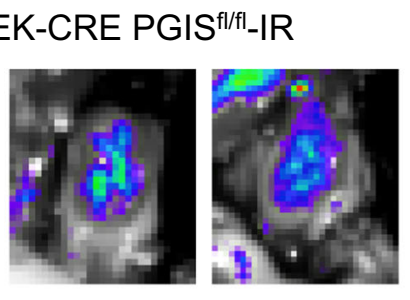

C

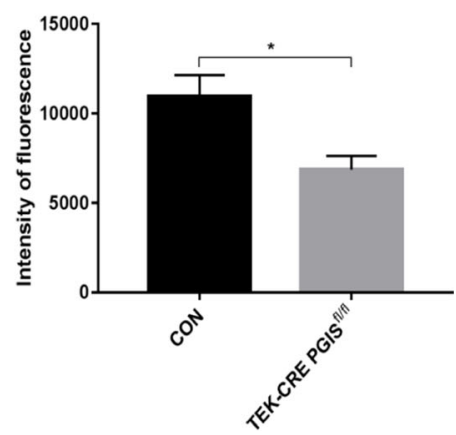

Fig. 9 Renal blood flow after reperfusion. a Electron microscopy images of the renal peritubular capillaries of the indicated groups are shown. Scale bars, $5 \mu \mathrm{m}$. b In vivo whole-body imaging of fluorescent microspheres following I/R surgery. $\mathbf{c}$ Quantification of the fluorescence

hypertension or COX1-mediated vasoconstriction, whether the interaction of $\mathrm{PGI}_{2}$ and TP is involved in the protective effect of PGIS/PGI in AKI remains to be explored.

$\mathrm{PGI}_{2}$ has been reported to play an important role in modulating blood pressure by coupling with the IP receptor to relax vascular smooth muscle and control renin release [16, 22]. NSAIDs that inhibit COX and thus endogenous prostanoid synthesis may compromise the control of blood pressure in subjects with pre-existing salt-sensitive hypertension [14, 22]. In the present study, we examined the effect of PGIS deletion on systemic blood pressure. The result showed that the blood pressure of the TEK-CRE PGIS ${ }^{\mathrm{f} / \mathrm{fl}}$ mice was not significantly different compared with wild-type mice, suggesting that the observed effect in the endothelial PGIS knockout was not mediated via its effect on blood pressure.

In our study, global deletion of the PGIS gene led to embryonic lethality, suggesting that the PGIS product is required for development. Mice with heterozygous PGIS deletion or with selective endothelial PGIS deletion were fertile and developed normally. No ischemic renal disorders were observed in heterozygous $\mathrm{PGI}_{2}$-deficient mice or endothelial $\mathrm{PGI}_{2}$-deficient TEK-CRE PGIS ${ }^{\mathrm{fl} / \mathrm{fl}}$ mice. Therefore, the observed effect of $\mathrm{PGI}_{2}$ deficiency on the kidney following $\mathrm{I} / \mathrm{R}$ injury does not seem to be caused by abnormal renal development, intensity. A total of 10 mice were included ( $n=6$ in the CON group and $n=4$ in the TEK-CRE PGIS ${ }^{\mathrm{fl} / \mathrm{fl}}$ group). The data are expressed as the mean \pm SEM and were analyzed by Student's unpaired $t$ test between two groups $(P=0.044)$. $* P<0.05$

although subtle developmental abnormality that may cause abnormal response to injury can not be excluded.

The protective effect of $\mathrm{PGI}_{2}$ against cellular stress has been reported [17, 23, 44]. However, the mechanism underlying its protective effect is incompletely understood and may vary according to the injury stresses. Several mechanisms through which PGIS and $\mathrm{PGI}_{2}$ exert their protective effects have been proposed, including anti-inflammatory mechanisms $[9,30,38,46]$, reducing oxidative stress $[11,41]$, and regulating renal blood flow [45]. It has been reported that prostacyclin and PPAR protect against I/RI by inducing an anti-inflammatory pathway [6]. Although we can show that PGIS deletion is associated with worsened kidney injury in an I/R model, PGIS deletion did not worsen the kidney injury in folic acid-induced AKI, which is a nephrotoxic model. Then, we used fluorescent microspheres to assess the effect of $\mathrm{PGI}_{2}$ on renal blood flow. Deletion of the PGIS gene in endothelial cells significantly reduced fluorescent microsphere accumulation in kidneys after reperfusion. A recent study showed that the restoration of microvascular perfusion is associated with reduced kidney injury [8]. However, this result is inconsistent with published results suggesting that the beneficial effect of $\mathrm{PGI}_{2}$ in renal I/R injury is not related to changes in renal blood flow [15]. The difference between these results may be due to 
how $\mathrm{PGI}_{2}$ was administered. Continuous infusion may cause hypotension and stimulate renin release, which would then block the reperfusion.

In summary, $\mathrm{PGI}_{2}$ expression was increased after I/Rinduced AKI. The PGIS and $\mathrm{PGI}_{2}$ deficits in mouse kidneys increased vulnerability to I/R-induced AKI. Iloprost, an ana$\log$ of $\mathrm{PGI}_{2}$, rescued the kidney from I/R-induced injury. This study provides evidence suggesting that PGIS-derived $\mathrm{PGI}_{2}$ can protect the kidney from acute injury caused by ischemic reperfusion and could be a potential preventive intervention for AKI.

Funding This study was supported by the National Natural Science Foundation of China (grants 81130075 and 31471101 ) and 985 project 985 III-YFX0302.

\section{Compliance with ethical standards}

Conflict of interest The authors declare that they have no conflicts of interest.

Ethical approval All procedures performed in studies involving animals were in accordance with the ethical standards of the institution or practice at which the studies were conducted.

Informed consent Informed consent was obtained from all individual participants included in the study.

Open Access This article is distributed under the terms of the Creative Commons Attribution 4.0 International License (http:// creativecommons.org/licenses/by/4.0/), which permits unrestricted use, distribution, and reproduction in any medium, provided you give appropriate credit to the original author(s) and the source, provide a link to the Creative Commons license, and indicate if changes were made.

\section{References}

1. Basile DP, Dwinell MR, Wang SJ, Shames BD, Donohoe DL, Chen S, Sreedharan R, Van Why SK (2013) Chromosome substitution modulates resistance to ischemia reperfusion injury in Brown Norway rats. Kidney Int 83:242-250

2. Bonventre JV, Weinberg JM (2003) Recent advances in the pathophysiology of ischemic acute renal failure. J Am Soc Nephrol 14: 2199-2210

3. Bonventre JV, Yang L (2011) Cellular pathophysiology of ischemic acute kidney injury. J Clin Invest 121:4210-4221

4. Breyer MD, Breyer RM (2000) Prostaglandin receptors: their role in regulating renal function. Curr Opin Nephrol Hypertens 9:23-29

5. Breyer MD, Breyer RM (2001) G protein-coupled prostaniod receptors and the kidney. Annu Rev Physiol 63:579-605

6. Chen HH, Chen TW, Lin H (2009) Prostacyclin-induced peroxisome proliferator-activated receptor- $\alpha$ translocation attenuates NF$\kappa \mathrm{B}$ and $\mathrm{TNF}-\alpha$ activation after renal ischemia-reperfusion injury. Am J Physiol Ren Physiol 297:F1109-F1118

7. Choi JH, Yu BP (1998) Dietary restriction as a modulator of agerelated changes in rat kidney prostaglandin production. $\mathrm{J}$ Nutr Health Aging 2:167-171
8. Collett JA, Corridon PR, Mehrotra P, Kolb AL, Rhodes GJ, Miller CA, Molitoris BA, Pennington JG, Sandoval RM, Atkinson SJ, Campos-Bilderback SB, Basile DP, Bacallao RL (2017) Hydrodynamic isotonic fluid delivery ameliorates moderate-tosevere ischemia-reperfusion injury in rat kidneys. J Am Soc Nephrol 28:2081-2092

9. Dorris SL, Peebles RS Jr (2012) $\mathrm{PGI}_{2}$ as a regulator of inflammatory diseases. Mediat Inflamm 2012:926968

10. Dreischulte T, Morales DR, Bell S, Guthrie B (2015) Combined use of nonsteroidal anti-inflammatory drugs with diuretics and/or renin-angiotensin system inhibitors in the community increases the risk of acute kidney injury. Kidney Int 88:396-403

11. Egan KM, Lawson JA, Fries S, Koller B, Rader DJ, Smyth EM, Fitzgerald GA (2004) COX-2-derived prostacyclin confers atheroprotection on female mice. Science 306:1954-1957

12. El-Haroun H, Clarke DL, Deacon K, Bradbury D, Clayton A, Sutcliffe A, Knox AJ (2008) IL-1 beta, BK, and TGF-beta1 attenuate PGI2-mediated cAMP formation in human pulmonary artery smooth muscle cells by multiple mechanisms involving p38 MAP kinase and PKA. Am J Phys Lung Cell Mol Phys 294:L553-L562

13. Feletou M, Verbeuren TJ, Vanhoutte PM (2009) Endotheliumdependent contractions in SHR: a tale of prostanoid TP and IP receptors. Br J Pharmacol 156:563-574

14. Fierro-Carrion GA, Ram CV (1997) Nonsteroidal antiinflammatory drugs (NSAIDs) and blood pressure. Am J Cardiol 80:775-776

15. Finn WF, Hak LJ, Grossman SH (1987) Protective effect of prostacyclin on postischemic acute renal failure in the rat. Kidney Int 32: 479-487

16. Francois H, Athirakul K, Howell D, Dash R, Mao L, Kim HS, Rockman HA, Fitzgerald GA, Koller BH, Coffman TM (2005) Prostacyclin protects against elevated blood pressure and cardiac fibrosis. Cell Metab 2:201-207

17. Goto Y, Yamaguchi S, Tamura M, Mochizuki H, Kurumatani H, Okano K, Miyamoto M (2014) A prostacyclin analog prevents the regression of renal microvascular network by inhibiting mitochondria-dependent apoptosis in the kidney of rat progressive glomerulonephritis. Prostaglandins Other Lipid Mediat 112:16-26

18. Hao CM, Breyer MD (2007) Physiologic and pathophysiologic roles of lipid mediators in the kidney. Kidney Int 71:1105-1115

19. Hao CM, Breyer MD (2008) Physiological regulation of prostaglandins in the kidney. Annu Rev Physiol 70:357-377

20. Harris PC, Torres VE (2014) Genetic mechanisms and signaling pathways in autosomal dominant polycystic kidney disease. J Clin Invest 124:2315-2324

21. Imig JD (2006) Eicosanoids and renal vascular function in diseases. Clin Sci 111:21-34

22. Jackson EK (1989) Relation between renin release and blood pressure response to nonsteroidal anti-inflammatory drugs in hypertension. Hypertension 14:469-471

23. Johannes T, Ince C, Klingel K, Unertl KE, Mik EG (2009) Iloprost preserves renal oxygenation and restores kidney function in endotoxemia-related acute renal failure in the rat. Crit Care Med 37:1423-1432

24. Kam Tao Li P, Burdmann EA, Mehta RL, World Kidney Day Steering Committee (2013) Acute kidney injury: global health alert. J Nephropathol 2(90-97):2013

25. Lameire N, Van Biesen W, Vanholder R (2005) Acute renal failure. Lancet 365:417-430

26. Levy JV (1980) Prostacyclin-induced contraction of isolated aortic strips from normal and spontaneously hypertensive rats (SHR). Prostaglandins 19:517-525

27. Lewington AJ, Cerda J, Mehta RL (2013) Raising awareness of acute kidney injury: a global perspective of a silent killer. Kidney Int 84:457-467 
28. Liu B, Zhang Y, Zhu N, Li H, Luo W, Zhou Y (2013) A vasoconstrictor role for cyclooxygenase-1-mediated prostacyclin synthesis in mouse renal arteries. Am J Physiol Ren Physiol 305:F1315F1322

29. Majed BH, Khalil RA (2012) Molecular mechanisms regulating the vascular prostacyclin pathways and their adaptation during pregnancy and in the newborn. Pharmacol Rev 64:540-582

30. Müller T, Dürk T, Blumenthal B, Herouy Y, Sorichter S, Grimm M, Panther E, Cicko S, Norgauer J, Idzko M (2010) Iloprost has potent anti-inflammatory properties on human monocyte-derived dendritic cells. Clin Exp Allergy 40:1214-1221

31. Narumiya S, FitzGerald GA (2001) Genetic and pharmacological analysis of prostanoid receptor function. J Clin Invest 108:25-30

32. Needleman P, Moncada S, Bunting S, Vane JR, Hamberg M, Samuelsson B (1976) Identification of an enzyme in platelet microsomes which generates thromboxane A2 from prostaglandin endoperoxides. Nature 261:558-560

33. Okumura M, Imanishi M, Yamashita T, Yamamura Y, Kim S, Iwao $\mathrm{H}$, Tanaka S, Fujii S (2000) Renal production of thromboxane and prostaglandins in a rat model of type 2 diabetes. Life Sci 66:371377

34. Oni L, Hawcutt DB, Turner MA, Beresford MW, McWilliam S, Barton C, Park BK, Murray P, Wilm B, Copple I, Floyd R, Peak M, Sharma A, Antoine DJ (2017) Optimising the use of medicines to reduce acute kidney injury in children and babies. Pharmacol Ther 174:55-62

35. Prieto-García L, Pericacho M, Sancho-Martínez SM, Sánchez Á, Martinez-Salgado C, López-Novoa JM, López-Hernández FJ (2016) Mechanisms of triple whammy acute kidney injury. Pharmacol Ther 167:132-145

36. Rosner MH, Okusa MD (2006) Acute kidney injury associated with cardiac surgery. Clin J Am Soc Nephrol 1:19-32

37. Smith WL (1992) Prostanoid biosynthesis and mechanisms of action. Am J Phys 263:F181-F191

38. Strassheim D, Riddle SR, Burke DL, Geraci MW, Stenmark KR (2009) Prostacyclin inhibits IFN-gamma-stimulated cytokine expression by reduced recruitment of $\mathrm{p} 300 / \mathrm{CBP}$ to STAT1 in a SOCS-1-independent manner. J Immunol 183:6981-6988
39. Tompers DM, Labosky PA (2004) Electroporation of murine embryonic stem cells: a step-by-step guide. Stem Cells 22:243-249

40. Vamecq J, Colet JM, Vanden Eynde JJ, Briand G, Porchet N, Rocchi S (2012) PPARs: interference with Warburg' effect and clinical anticancer trials. PPAR Res 2012:304760

41. Yang C, DeMars KM, Alexander JC, Febo M, Candelario-Jalil E (2017) Sustained neurological recovery after stroke in aged rats treated with a novel prostacyclin analog. Stroke 48:1948-1956

42. Yang L, Xing G, Wang L, Wu Y, Li S, Xu G, He Q, Chen J, Chen M, Liu X, Zhu Z, Yang L, Lian X, Ding F, Li Y, Wang H, Wang J, Wang R, Mei C, Xu J, Li R, Cao J, Zhang L, Wang Y, Xu J, Bao B, Liu B, Chen H, Li S, Zha Y, Luo Q, Chen D, Shen Y, Liao Y, Zhang Z, Wang X, Zhang K, Liu L, Mao P, Guo C, Li J, Wang Z, Bai S, Shi S, Wang Y, Wang J, Liu Z, Wang F, Huang D, Wang S, Ge S, Shen Q, Zhang P, Wu L, Pan M, Zou X, Zhu P, Zhao J, Zhou M, Yang L, Hu W, Wang J, Liu B, Zhang T, Han J, Wen T, Zhao M, Wang H (2015) Acute kidney injury in China: a cross-sectional survey. Lancet 386:1465-1471

43. Yang Y, Song M, Liu Y, Liu H, Sun L, Peng Y, Liu F, Venkatachalam MA, Dong Z (2016) Renoprotective approaches and strategies in acute kidney injury. Pharmacol Ther 163:58-73

44. Yano T, Itoh Y, Kubota T, Sendo T, Oishi R (2004) A prostacyclin analog beraprost sodium attenuates radiocontrast media-induced LLC-PK1 cells injury. Kidney Int 65:1654-1663

45. Yokoyama C, Yabuki T, Shimonishi M, Wada M, Hatae T, Ohkawara S, Takeda J, Kinoshita T, Okabe M, Tanabe T (2002) Prostacyclin-deficient mice develop ischemic renal disorders, including nephrosclerosis and renal infarction. Circulation 106: 2397-2403

46. Zhou W, Hashimoto K, Goleniewska K, O'Neal JF, Ji S, Blackwell TS, Fitzgerald GA, Eqan KM, Geraci MW, Peebles RS Jr (2007) Prostaglandin $\mathrm{I}_{2}$ analogs inhibit proinflammatory cytokine production and $\mathrm{T}$ cell stimulatory function of dendritic cells. J Immunol 178:702-710

47. Zuk A, Bonventre JV (2016) Acute kidney injury. Annu Rev Med 67:293-307 